\title{
Clinical evaluation of zaleplon in the treatment of insomnia
}

This article was published in the following Dove Press journal:

Nature and Science of Sleep

17 July 2010

Number of times this article has been viewed

\section{Marieke M Ebbens Joris C Verster}

Utrecht Institute for Pharmaceutical Sciences, Division of Pharmacology, Utrecht University, The Netherlands
Correspondence: Joris CVerster Utrecht Institute for Pharmaceutical Sciences, Division of Pharmacology, Utrecht University, PO Box 80082, 3508TB, Utrecht, The Netherlands $\mathrm{Tel}+3 \mathrm{I} 302536909$

Fax +3I 302537900

Email j.c.verster@uu.nl
Abstract: Zaleplon is a pyrazolopyrimidine hypnotic used for the treatment of insomnia. Zaleplon binds preferentially at the $\alpha 1 \beta 2 \gamma 2$ subunit of gamma aminobutyric acid type $\mathrm{A}\left(\mathrm{GABA}_{\mathrm{A}}\right)$ receptors in the central nervous system, and has a half-life of about one hour. Efficacy studies show that zaleplon is a suitable hypnotic for sleep initiation purposes. However, because of its short half-life, zaleplon is less effective in sleep maintenance when compared with other hypnotics. Nevertheless, zaleplon does increase total sleep time. No rebound effects are observed after treatment discontinuation. The use of zaleplon is relatively safe. Adverse effects are mild and of short duration. No important interactions have been reported, and there is no evidence of abuse potential. Relative to benzodiazepine hypnotics, the biggest advantage of zaleplon is that current evidence suggests it does not produce residual next-day effects. As early as four hours after intake of zaleplon, no effects on cognitive, memory, psychomotor performance, and the ability to drive a car have been reported. Future studies should confirm these findings, and comparisons with new nonbenzodiazepine hypnotics should determine the importance of zaleplon in the future treatment of insomnia.

Keywords: zaleplon, zolpidem, hypnotics, efficacy, safety, residual effects

\section{Introduction}

People with insomnia have problems initiating and/or maintaining sleep. As a result, they do not wake up refreshed in the morning, and often experience daytime sleepiness that, in turn, may affect daily activities, such as driving a car or on-the-job performance. Insomnia is experienced by about $15 \%-30 \%$ of the population during their lifetime, is comorbid with many diseases and psychiatric illnesses and may significantly reduce quality of life. ${ }^{1}$ Therefore, insomnia is a common disease with significant socioeconomic consequences.

The treatment of insomnia comprises both pharmacologic and behavioral approaches. $^{2}$ In many instances, improvement of sleep hygiene may relieve problems initiating sleep. ${ }^{3}$ Cognitive behavioral therapy can be helpful to improve sleep hygiene. For many decades, pharmacologic treatment of insomnia was dominated by the use of benzodiazepine hypnotics. Although these drugs proved to be effective for the treatment of short-term insomnia, next-day residual effects, such as reduced alertness and sleepiness, could significantly affect daily activities. Development of tolerance, dependence, withdrawal effects, and abuse potential led to the development of new hypnotic drugs. These nonbenzodiazepine hypnotics, collectively called the Z-drugs, include zopiclone, zolpidem, and zaleplon. During the past decade, variants 
of these drugs, such as eszopiclone, have been marketed as well. The primary purpose of developing these new hypnotics was to provide an improved adverse effect profile, but with at least similar efficacy when compared with benzodiazepine hypnotics. This review focuses on zaleplon, the newest among the Z-drugs.

In the past, four articles have reviewed the clinical efficacy of zaleplon. ${ }^{4-7}$ An excellent review of the preclinical development of zaleplon can be read elsewhere. ${ }^{8}$ The current review updates previous ones by including more recent studies that have been performed with zaleplon. In addition, when compared with previous reviews, the current review has a stronger focus on potential residual effects on daytime functioning.

For this review, the PubMed and Embase databases and the Cochrane Library were systematically searched, using the search term "zaleplon". This yielded 954 articles. Articles including experimental data were used for this review. After reading the articles, 886 articles were excluded, because they were general articles on insomnia or reviews (517), included no relevant data (129), were animal studies (21), general guidelines on insomnia treatment (76), written in languages other than English (62), discussed drug synthesis and analysis (40), or were cost-benefit analyses and letters to the editor (43). The remaining 66 articles are discussed in this review.

\section{Pharmacology}

Zaleplon is a pyrazolopyrimidine hypnotic drug indicated for the short-term (ie, 1-2 week) management of insomnia. Its chemical structure is shown in Figure 1. Like benzodiazepine hypnotics, zaleplon acts on gamma aminobutyric acid type $A\left(\mathrm{GABA}_{\mathrm{A}}\right)$ receptors in the central nervous system (CNS). $\mathrm{GABA}_{\mathrm{A}}$ receptors are organized through the membrane as pentameric proteins surrounding a central pore that forms the $\mathrm{Cl}^{-}$ion channel. Most GABA ${ }_{\mathrm{A}}$ receptors consist of two $\alpha$ subunits, two $\beta$ subunits and $\alpha, \delta$, or other subunit. In humans, six different $\alpha$ subunits, three $\beta$ subunits, three $\gamma$ subunits, a $\delta$, an $\varepsilon$, a $\pi$, and a $\theta$ subunit are identified. Approximately $75 \%-80 \%$ of the $\mathrm{GABA}_{\mathrm{A}}$ receptors contain a $\gamma 2$ subunit. The most common $\mathrm{GABA}_{\mathrm{A}}$ receptor consists of two $\alpha 1$ subunits, two $\beta 2$ subunits and a $\gamma 2$ subunit. ${ }^{9}$ The classic benzodiazepines bind to $\mathrm{GABA}_{\mathrm{A}}$ receptors at the interface of an $\alpha$ and $\gamma$ subunit. Benzodiazepines are active at sites where a $\gamma 2$ subunit is coupled with one of the subunits, $\alpha 1,2,3$, or $5 .{ }^{9}$ The anxiolytic effect and myorelaxant actions of benzodiazepines are thought to be mediated by the $\alpha 2$-containing receptors, whereas the sedative-hypnotic action appears to be mediated through the $\alpha 1$ receptors. ${ }^{10}$

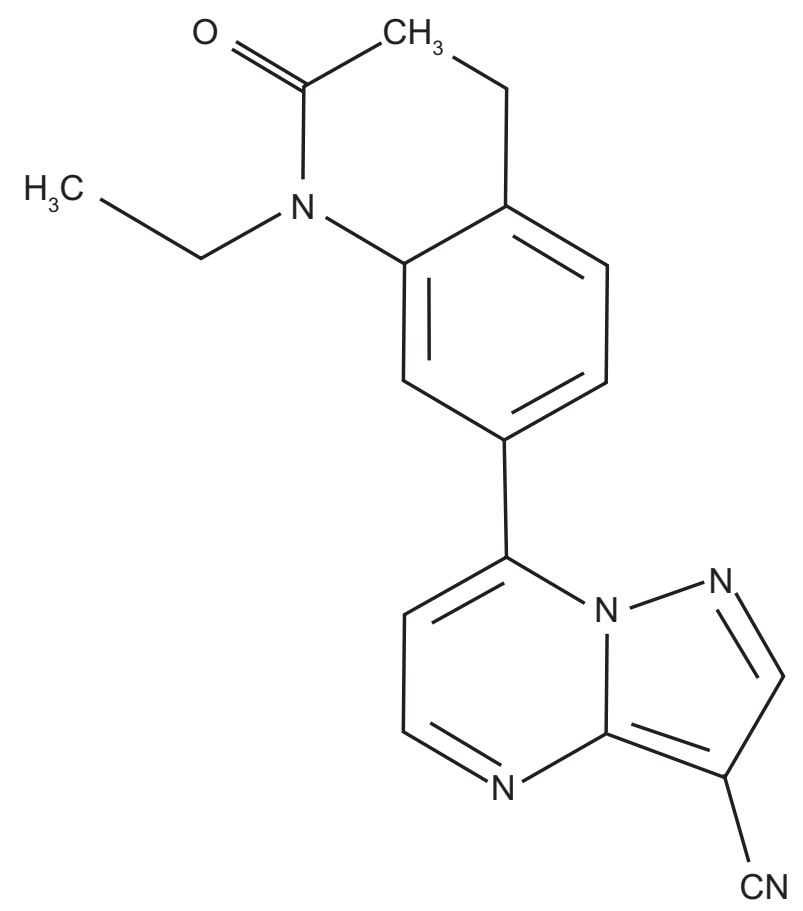

Figure I Chemical structure of zaleplon (N-[3-(3-cyanopyrazolo[I,5-a]pyrimidin-7 yl)phenyl)]-N-ethylacetamide.

Benzodiazepine hypnotics bind nonselectively to the benzodiazepine recognition site of the $\mathrm{GABA}_{\mathrm{A}}$ receptor complex. ${ }^{11,12}$ Whereas most benzodiazepine hypnotics bind to all $\mathrm{GABA}_{\mathrm{A}}$ receptors with similar affinity, zaleplon and zolpidem have a more selective affinity for some of its subunits. Zaleplon and zolpidem prefer the $\alpha 1 \beta 2 \gamma 2$ subunit combination, which represents the combination that is most abundantly present in the brain. In addition, zaleplon (but not zolpidem) recognizes $\alpha 2$ and $\alpha 3$ receptors.

\section{Pharmacokinetics}

Typical pharmacokinetic data for zaleplon and zolpidem are summarized in Table 1. Zaleplon is rapidly absorbed. The time to maximum plasma concentration $\left(\mathrm{T}_{\max }\right)$ and elimination half-life $\left(\mathrm{t}_{1 / 2}\right)$ are approximately one hour, with a narrow range of individual variation. ${ }^{13-16}$ The absolute bioavailability of zaleplon is $30 \%$ in both men and women. Zaleplon exhibits dose-proportional kinetics, both in peak plasma concentration $\left(\mathrm{C}_{\max }\right)$ and area under the concentration-time curve. More than $99 \%$ of zaleplon is metabolized by the liver, and less than $1 \%$ is eliminated unchanged via the urine. Zaleplon is metabolized by aldehyde oxidase to 5-oxo-zaleplon or by CYP3A4 to desethylzaleplon which is converted to 5-oxodesethylzaleplon by aldehyde oxidase. These metabolites are further metabolized by conjugation and are eliminated in urine. ${ }^{17}$ The metabolites of zaleplon are pharmacologically inactive. ${ }^{18}$ 
Table I Comparative pharmacokinetic data for zaleplon and zolpidem

\begin{tabular}{|c|c|c|c|c|}
\hline Pharmacokinetics & Zaleplon 10 mg & Zaleplon $20 \mathrm{mg}$ & Zolpidem 10 mg & Zolpidem $20 \mathrm{mg}$ \\
\hline $\mathrm{C}_{\max }(\mathrm{ng} / \mathrm{mL})$ & $26.0 \pm 4.4$ & $49.0 \pm 5.7$ & $125 \pm 15$ & $232 \pm 17$ \\
\hline $\mathrm{T}_{\max }$ (hours) & $1.1 \pm 0.17$ & $\mathrm{I} . \mathrm{I} \pm 0.2 \mathrm{I}$ & $1.7 \pm 0.3$ & $2.0 \pm 0.3$ \\
\hline $\mathrm{T}_{1 / 2}$ (hours) & $1.01 \pm 0.05$ & $0.98 \pm 0.03$ & $2.0 \pm 0.15$ & $2.2 \pm 0.26$ \\
\hline AUC (ng/mL/hour) & $42.1 \pm 5.5$ & $93.2 \pm 15$ & $408 \pm 48$ & $889 \pm 110$ \\
\hline Clearance* $(\mathrm{mL} / \mathrm{min})$ & $4436 \pm 457$ & $4299 \pm 537$ & $378 \pm 52$ & $34 I \pm 38$ \\
\hline
\end{tabular}

Notes: Mean $( \pm \mathrm{SE})$ values from 10 healthy male volunteers. *Apparent oral clearance.

Abbreviations: $C_{\max }$, peak plasma concentration; $T_{\max }$, time at which $C_{\max }$ occurs; $A \cup C$, area under the plasma concentration versus time curve; $T_{1 / 2}$, elimination half-life. Data adapted from Greenblatt et al. ${ }^{15}$

\section{Efficacy}

Studies examining the efficacy of short-term and long-term use of zaleplon have focused on the drug's ability to initiate and maintain sleep. The most common endpoints in these clinical trials were latency to falling asleep, number of nightly awakenings, and total sleep time. Additionally, polysomnographic data were examined to determine if zaleplon alters sleep architecture.

\section{Short-term use ( $<2$ weeks)}

A small three-night study in nine insomniacs and two neurotic patients with insomnia revealed that zaleplon $5 \mathrm{mg}$ and $10 \mathrm{mg}$ was effective in shortening sleep latency and slow-wave sleep latency. ${ }^{19}$ The treatment nights were followed by two withdrawal nights that showed no signs of rebound insomnia. A much larger study by Ancoli-Israel et al examined sleep in 549 elderly outpatients after two weeks of double-blind treatment with zaleplon $5 \mathrm{mg}$ or $10 \mathrm{mg}$, zolpidem $5 \mathrm{mg}$, or placebo. ${ }^{20}$ Zaleplon and zolpidem significantly reduced sleep latency and increased total sleep time. Relative to placebo, zaleplon reduced sleep latency by 15-20 minutes and increased total sleep time by about 40 minutes. Drake et al showed that zaleplon 10-60 mg produced significant dose-dependent decreases in latency to persistent sleep in chronic insomniacs. ${ }^{21}$ However, only the $60 \mathrm{mg}$ dose of zaleplon produced significant increases in total sleep time when compared with placebo. All doses of zaleplon tended to increase the proportion of stages 3 and 4 sleep.

A double-blind, crossover study using a VAS scale to assess treatment satisfaction in 53 patients after administration of a single dose of zolpidem $10 \mathrm{mg}$ or zaleplon $10 \mathrm{mg}$ reported that $62 \%$ of patients preferred zolpidem. ${ }^{22}$

In another study, 47 patients with insomnia received either zaleplon $10 \mathrm{mg}$ or $20 \mathrm{mg}$ or zolpidem $10 \mathrm{mg}$ or $20 \mathrm{mg}$ for two weeks and completed a subjective sleep dysfunction rating scale assessment. ${ }^{23}$ Scores were significantly improved in both groups and no significant differences were reported between the treatments. Walsh et al examined the efficacy of zaleplon $5 \mathrm{mg}$ and $10 \mathrm{mg}$, triazolam, versus placebo in 132 patients with primary insomnia. ${ }^{24}$ Patients received one of these treatments for 14 days. Polysomnographic data showed that zaleplon significantly shortened latency to persistent sleep during the first nights, but not thereafter. In contrast with triazolam, zaleplon did not significantly increase total sleep time, nor did it reduce the number of nightly awakenings. These findings indicate that zaleplon is effective to some extent in initiating sleep and increasing total sleep time.

\section{Long term use ( $>2$ weeks)}

Three studies examined the efficacy of zaleplon when using the drug for more than two weeks. In the first study, 615 adult insomniac patients received zaleplon 5, 10, or $20 \mathrm{mg}$, zolpidem $10 \mathrm{mg}$, or placebo for 28 nights. Zaleplon $10 \mathrm{mg}$ and $20 \mathrm{mg}$ significantly decreased sleep latency during all four weeks of treatment. ${ }^{25}$ For zaleplon $5 \mathrm{mg}$, this effect was significant during the first three weeks of treatment. The highest dose of zaleplon also significantly increased total sleep time. Zolpidem $10 \mathrm{mg}$ significantly decreased sleep latency, increased total sleep time, and improved sleep quality. Similar findings were reported by the second study. ${ }^{26}$

In a double-blind study, 113 adult patients with primary insomnia were treated for 35 days with either zaleplon $10 \mathrm{mg}$ or placebo. ${ }^{27}$ Zaleplon significantly shortened sleep latency. No consistent effect was found on total sleep time and zaleplon did not affect sleep architecture. These studies suggest that the improvements of sleep quality and duration produced by zaleplon persist during long-term treatment.

\section{Elderly}

Insomnia is common among the elderly, and as a result they are overrepresented among patients using hypnotic drugs. Drug dosages are often adapted to half the recommended adult dose. In the case of zaleplon, $5 \mathrm{mg}$ is commonly prescribed instead of $10 \mathrm{mg}$. A placebo-controlled study evaluated the 
efficacy and safety of zaleplon $5 \mathrm{mg}$ and $10 \mathrm{mg}$ in 422 elderly outpatients with insomnia. ${ }^{28}$ Sleep latency, sleep duration, number of awakenings, and sleep quality were recorded for two weeks by using questionnaires. Both dosages of zaleplon significantly reduced subjective sleep latency by 10 to 20 minutes. Relative to placebo, zaleplon $10 \mathrm{mg}$ also significantly improved sleep quality. Walsh et al treated 48 elderly patients (aged 60-80 years) suffering from chronic insomnia with zaleplon 2, 5, and $10 \mathrm{mg}$ or placebo. ${ }^{29}$ Polysomnographic measurements showed that latency to persistent sleep was shortened significantly with all three zaleplon doses. Subjective sleep latency was reduced significantly, and total sleep time was significantly increased with zaleplon $5 \mathrm{mg}$ and $10 \mathrm{mg}$. In an open-label study, 15 psychiatric inpatients were treated with the sedative antidepressant drug trazodone 50-100 mg or zaleplon 10-20 mg, using the medication on an as-needed basis. ${ }^{30}$ Whereas trazodone was more successful in promoting and sustaining sleep, residual daytime effects were much less often reported by patients using zaleplon.

One study followed a group of elderly patients (65-95 years) who used zaleplon $5 \mathrm{mg}$ or $10 \mathrm{mg}$ for up to one year. Initial treatment improvement persisted in terms of significantly reduced sleep onset time, increased duration of sleep, and reduced number of nocturnal awakenings (Figure 2). ${ }^{31}$

\section{Daytime sleep and shift work}

Zaleplon $10 \mathrm{mg}$ improved daytime sleep in 12 rested healthy subjects. ${ }^{32}$ When woken after 3.5 hours, no impairment was found on cognitive, memory, and psychomotor performance. The effect of zaleplon $10 \mathrm{mg}$ and temazepam $20 \mathrm{mg}$ on afternoon sleep (5.30-10.00 p.m.) and effects on performance and alertness during a subsequent night shift were examined in 11 subjects. ${ }^{33}$ Improvement of sleep quality was significantly more pronounced after taking temazepam. Zaleplon did not differ from placebo for any sleep parameter. Temazepam and zaleplon did not affect performance on tests done after waking up (vigilance/tracking and a complex information processing task). Although these studies had relatively small sample sizes, the results indicate that zaleplon is effective in promoting daytime sleep, without residual effects after awaking.

\section{Efficacy of zaleplon at high altitude}

Few studies have tested the effects of zaleplon at high altitude. Mountain climbers can experience respiratory problems and sleep disturbances when at altitude. ${ }^{34}$ Poor sleep may affect cognitive and psychomotor functioning and reduce daytime alertness which are essential for safe mountain climbing. Beaumont et al tested 12 healthy men who slept for a night in a decompression chamber at a simulated altitude of $4000 \mathrm{~m} \cdot{ }^{35}$ In this double-blind, crossover study, zolpidem $10 \mathrm{mg}$, zaleplon $10 \mathrm{mg}$, or placebo were administered at bedtime. Polysomnographic and respiratory measures showed that both zaleplon and zolpidem improved slow-wave sleep at high altitude, without negatively affecting respiratory functions. Cognitive and physical performance, examined the next morning at sea level conditions, was not affected by zaleplon or zolpidem. The authors then tested the efficacy of the drugs at a comparable altitude on a mountain $(3613 \mathrm{~m}) \cdot{ }^{36}$ Sleep and respiratory functions were significantly disturbed at high altitude on placebo, whereas zaleplon and zolpidem significantly improved sleep quality and respiratory
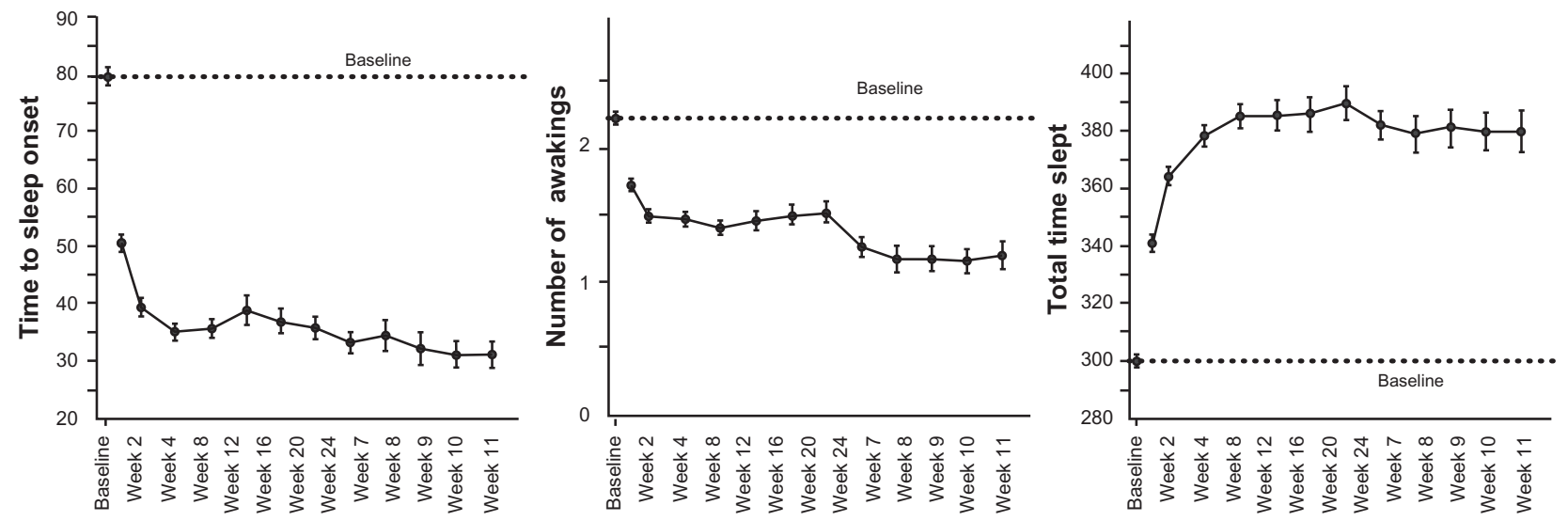

Figure 2 Mean (standard deviation) time to sleep onset (left panel), mean (standard deviation) number of awakenings (middle panel), and mean total time slept (right panel) in elderly patients using zaleplon nightly for 6-12 months.

Copyright @ 2005. World Association of Sleep Medicine. All rights reserved. Adapted with permission from Ancoli-lsrael S, Richardson GS, Mangano RM, Jenkins L, Hall P, Jones WS. Long term use of sedative hypnotics in older patients with insomnia. Sleep Med. 2005;6(2):107-13. 
functioning. Daytime cognitive functioning, examined by the digit symbol substitution test (DSST) showed that, relative to the baseline level $(800 \mathrm{~m})$, performance at high altitude was significantly worse after all treatments, including placebo. However, the authors found no impairment after administration of zaleplon or zolpidem. ${ }^{36}$

In a double-blind, crossover design, 12 nonacclimatized male soldiers spent four nights at high altitude $(3613 \mathrm{~m}){ }^{37}$ Subjects exercised for three days at altitude, followed by a treatment night (zaleplon, zolidem, or placebo). Arterial oxygen saturation, heart rate variability, and mountain sickness were recorded. Both zolpidem and zaleplon improved sleep and physical fitness at altitude.

\section{Rebound effects}

After discontinuation of hypnotic drugs, rebound effects may occur. Commonly reported rebound effects are prolonged sleep latency, reduced total sleep time, and increased number of awakenings. Often these rebound effects are subjectively reported by patients completing sleep diaries. In contrast with zolpidem, clinical trials that discontinued the use of zaleplon $5 \mathrm{mg}$ and $10 \mathrm{mg}$ reported no significant rebound symptoms. ${ }^{20,25-27}$ In the elderly, a weak indication of rebound insomnia was found after discontinuation of treatment with zaleplon $10 \mathrm{mg}$, but not zaleplon $5 \mathrm{mg} .{ }^{28}$ In elderly outpatients discontinuing zaleplon 5 or $10 \mathrm{mg}$ after 6-12 months, no rebound insomnia was observed..$^{31}$

\section{Safety and tolerability}

Adverse effects from zaleplon are of relative short duration, milder, and resolve more quickly when compared with those of benzodiazepine hypnotics. In 1998-2004, Texas poison control centers recorded adverse effects reported by patients using zolpidem or zaleplon. The most frequently reported adverse effects for zaleplon and zolpidem were drowsiness, slurred speech, hallucinations, ataxia, tachycardia, dizziness, confusion, and vomiting. ${ }^{38}$

In a parallel-group design, oral doses of $1,5,15,30$, or $60 \mathrm{mg}$ of zaleplon were tested in five healthy male volunteers. Zaleplon was well tolerated and produced no significant changes in vital signs, the electroencephalogram, the electrocardiogram, or hematologic and clinical chemistry parameters. ${ }^{13}$ Dose-dependent presence and severity of adverse events were reported. In this small study, impaired concentration, difficulty focusing, and impaired coordination were most frequently reported.
Studies performed at stimulated high altitude ${ }^{35}$ and actual high altitude ${ }^{36}$ showed that zaleplon did not alter respiratory measures. ${ }^{35,36}$ Zaleplon $10 \mathrm{mg}$ administered to 15 patients with obstructive sleep apnea while on continuous positive airway pressure treatment was shown to be safe. Zaleplon did not significantly alter the apnea-hypopnea index or affect respiratory parameters. ${ }^{39}$

In 10 patients on maintenance hemodialysis and suffering from insomnia, Pittsburgh questionnaire scores indicated that zaleplon $5 \mathrm{mg}$ and $10 \mathrm{mg}$ significantly improved overall sleep quality, reduced sleep latency, but did not prolong total sleep time. ${ }^{40}$ Zaleplon did not affect any dialysis parameters.

An open-label study in five lactating mothers showed that zaleplon $10 \mathrm{mg}$ taken by a nursing mother is transferred through breast milk to her infant. However, this occurs in very small quantities $(0.013 \%-0.017 \%$ of the maternal dose $)$ that are unlikely to be clinically important. ${ }^{41}$

\section{Adverse reactions after overdose}

Few case studies have been published that describe the effects of zaleplon overdose. ${ }^{42-45}$ Liskow described a 14-year-old boy who took three tablets instead of one $10 \mathrm{mg}$ tablet zaleplon, three weeks after treatment initiation. ${ }^{42}$ The boy was found sleepwalking and his parents took him to hospital. Bhatia et al 2001 described a case of a healthy woman who experienced zaleplon-induced illusions and visual hallucinations, and a feeling of depersonalization within three minutes of ingesting zaleplon $10 \mathrm{mg}$ at bedtime. ${ }^{43}$ The duration of events was limited to 15 minutes, but lightheadedness and fatigue persisted until the next day. An overdose of zaleplon in combination with alcohol was described by Hojer et al. ${ }^{44}$ A 55-year-old man with bluish-green urine had taken an unknown amount of zaleplon in combination with whiskey. The patient was sedated and had only weak responses. Initial intravenous administration of flumazenil $1 \mathrm{mg}$ immediately woke the patient, but three hours thereafter the patient went into a coma. An additional dose of flumazenil was needed to wake this patient. No arousing effect was observed after administering flumazenil $0.5 \mathrm{mg}$ to a 68 -year-old woman who had an overdose of zaleplon and trimipramine. This woman also had bluish-green urine. After two days the patient was fully awake.

Another case described a 24-year-old woman who took about 28 zaleplon tablets. She had bluish-green discoloration of lips, urine, and emesis, was confused and sleepy, and experienced visual hallucinations. The following day the 
patient was alert and recovered. ${ }^{45}$ Bluish-green urine is an indicator of zaleplon abuse, and is probably due to the indigo carmine used in zaleplon capsules. ${ }^{45}$

\section{Interactions}

In contrast with benzodiazepine hypnotics, few clinically important interactions have been reported for zaleplon. This may reflect the fact that zaleplon is a relatively new hypnotic drug, and only a few studies have been done to investigate interactions. ${ }^{46}$ However, few interactions have been studied. There is no significant interaction between zaleplon and ibuprofen ${ }^{47}$ or digoxin. ${ }^{48}$ Also, coadministration of zaleplon $20 \mathrm{mg}$ and thioridazine $50 \mathrm{mg}$ in 12 healthy subjects did not change the pharmacokinetic profile of either drug. Pharmacodynamic interactions were investigated, with only a significant difference in reaction time found between thioridazine and zaleplon versus thioridazine alone at one hour after administration. This indicates that there is an additive effect of zaleplon and thioridazine when these agents are coadministered. A supra-additive interaction was found for the DSST. However, due to the short half-life of zaleplon, the duration of maximal effect is four hours. The conclusion of the researchers therefore was that thioridazine $50 \mathrm{mg}$ and a nighttime dose of zaleplon $10 \mathrm{mg}$ can safely be administered together. ${ }^{49}$

Other potential, as yet undiscovered, interactions include those with CYP3A4 inhibitors or inducers because this is the main elimination route for zaleplon. As outlined in the summary of product characteristics, the interaction between erythromycin (a strong CYP3A4 inhibitor) caused a 34\% higher plasma concentration of zaleplon. Dose reduction is not indicated, but it is advised to inform patients of the larger sedating effect. Also, cimetidine causes a 85\% increase in plasma zaleplon concentration because it inhibits both the primary (aldehyde oxidase) and secondary (CYP3A4) elimination route of zaleplon. The combination of zaleplon and cimetidine is therefore not recommended. Combination of zaleplon with other hypnosedative drugs or alcohol can produce an additional sedative effect.

\section{Abuse potential}

A dose-ranging study by Beer et al did not report increased drug-liking scores when administering zaleplon dosages up to $60 \mathrm{mg}$ to healthy volunteers. ${ }^{13}$ In 14 healthy volunteers with a history of drug abuse, Rush et al tested the abuse potential of zaleplon $25 \mathrm{mg}, 50 \mathrm{mg}$, and $75 \mathrm{mg}$, triazolam $0.25 \mathrm{mg}$, $0.5 \mathrm{mg}$, and $0.75 \mathrm{mg}$, and placebo. ${ }^{50} \mathrm{~A}$ number of drug effect questionnaires were administered. In addition, a memory and psychomotor test battery were performed at fixed intervals up to 24 hours after intake. Although the duration of effects was shorter for zaleplon, both zaleplon and triazolam produced comparable dose- and time-related effects on the drug-liking questionnaires and psychometric tests. Subjective ratings of drug-liking suggest that, at higher dosages, zaleplon and triazolam have comparable abuse potential.

\section{Residual effects and daytime functioning}

Because the purpose of hypnotic drugs is to initiate or maintain sleep, there is a risk of sedative effects persisting after waking up and affecting cognitive functioning. Reduced daytime alertness and residual cognitive, memory, and psychomotor impairment have been reported for most hypnotic drugs. The following section summarizes results from studies that have examined the residual effects of zaleplon. The most commonly used psychometric tests are described in Table 2.

\section{Immediate effects}

A couple of studies examined the effects of zaleplon immediately after ingestion. These studies were performed during the daytime and no sleep was allowed. Subjects were tested for several hours after intake of zaleplon, and regular blood samples were taken to establish the pharmacokinetic profile of zaleplon.

In one of the early studies in healthy volunteers, Allen et al showed that whereas impairment by lorazepam $2 \mathrm{mg}$ persisted for 3-5 hours after intake, the effects on psychomotor performance and memory functioning with zaleplon $20 \mathrm{mg}$ were much less pronounced and lasted only one hour. ${ }^{51}$

Greenblatt et al examined the effects of zaleplon $10 \mathrm{mg}$ and $20 \mathrm{mg}$ and zolpidem $10 \mathrm{mg}$ and $20 \mathrm{mg}$ on self-reported sedation, DSST performance, and brain activity up to eight hours after intake in 10 healthy male volunteers. ${ }^{15}$ Dosedependent performance impairment was found for both drugs, which was significantly correlated with plasma concentrations. Memory functioning, measured 1.5 hours after intake, was also impaired for zolpidem, but not for zaleplon. Impairment after zolpidem was much more pronounced when compared with zaleplon.

Another study in 10 healthy volunteers examined the pharmacokinetic and pharmacodynamic profiles of zaleplon $10 \mathrm{mg}$ and $20 \mathrm{mg}$ and zolpidem $10 \mathrm{mg}$ and $20 \mathrm{mg} .{ }^{14}$ Blood samples were taken and subjects performed the DSST at fixed intervals. A word learning test was performed 1.5 hours after intake (immediate recall) and after eight 
Table 2 Description of commonly used performance tests

Digit symbol substitution test: Symbols are matched to numbers $(0-9)$. Subjects are instructed to copy as many symbols to a list of numbers as possible within a given time. Parameters of the test are number of correct symbols and percentage of errors.

Reaction time test: Subjects are instructed to push a button as soon as possible in response to a stimulus. The response can be either simple or complex. Parameters of the test are reaction speed and percentage of errors.

Tracking test: In this eye-hand coordination test subjects have to keep a moving bar at a steady position on the computer screen. Parameter is the tracking error.

Sternberg memory scanning test: In this working memory test, subjects have to recall a number of sets of $\mathrm{I}-5$ digits. After memorizing a set, a digit appears on the computer screen. Subjects have to indicate by button press if the digit was part of the learned set. Parameters are reaction time and percentage of errors.

Divided attention test: Two or more tests are performed simultaneously. Often divided attention test is a combination of a tracking test with the Sternberg memory scanning test or a reaction time test.

Word learning test: A list of words is learned. Recall is tested directly after learning (immediate recall) and one or more hours thereafter (delayed recall). Often, recognition tests are included in which the learned list is shown mixed with words that were not learned. Parameter is the number of correct words.

Logical reasoning: A statement is followed by several possible conclusions that can be drawn from the statement. Only one can be drawn by logical reasoning. Parameter is the number of correct answers.

Serial subtraction: Subjects have to subtract a number from a previous one (eg, count backwards from 100 in sevens). Parameter is the number of errors.

Paired associate learning: Subjects are shown a set of word pairs that should be learned. Subjects are then shown a list of words. They have to write down the correct other word of each pair. Parameter measured is the number of errors.

Digit span: A test to measure memory span. A digit is shown on the computer screen. When it disappears, the subject has to enter the digit. Then two digits appear (the first one and a new one) and the subject has to retype those. This procedure continues until the subject makes a mistake. Parameter is the number of correct digits.

hours (delayed recall). When compared with placebo, DSST was impaired for up to 6 hours after both zaleplon and zolpidem intake. Impairment after zolpidem was much more pronounced when compared with zaleplon. In contrast with zaleplon, zolpidem also significantly impaired word learning and recall. In line with these findings, subjective sedation scores were of a greater magnitude and longer duration after intake of zolpidem.

Paul et al examined psychomotor performance in 23 healthy volunteers, $1-7$ hours after intake of zaleplon $10 \mathrm{mg}$, zopiclone $7.5 \mathrm{mg}$, temazepam $15 \mathrm{mg}$, melatonin $6 \mathrm{mg}$, and placebo. ${ }^{52}$ All treatments except melatonin impaired performance on tests measuring serial reaction time, logical reasoning, serial subtraction, and multitasking. Figure 3 shows the impairment over time on the serial reaction time test. Impairment for zaleplon was significant up to 3.25 hours after intake, but much shorter when compared with zopiclone and temazepam (up to 6.25 and 5.25 hours after intake, respectively).

Polysomnographic measurement of total sleep and sleep latency during four minute periods with eyes closed immediately after performing the psychomotor test battery revealed that all treatments produced more sleep, shorter sleep latency, and more drowsiness. ${ }^{53}$

Postural instability is common when using benzodiazepine hypnotics and zopiclone. ${ }^{54}$ Balance problems are often the cause of falls and hip fractures. ${ }^{55}$ Postural instability is doseand time-dependent, and most profound at peak plasma concentration (ie, during the night). The latter may be particularly risky for patients who wake up during the night. In a daytime study in 16 health volunteers allowed one hour of sleep, body balance was examined up to seven hours after treatment with zaleplon $10 \mathrm{mg}$ or placebo. ${ }^{56}$ Subjects also performed several cognitive and performance tests. Zaleplon $10 \mathrm{mg}$ significantly impaired body balance and performance on most of the tests up to two hours after intake. Symptoms related to drowsiness were reported significantly more often during the first three hours after intake, but not thereafter. Memory was impaired for up to four hours after intake of zaleplon.

To determine a possible interaction with alcohol, the effects of triazolam $0.25 \mathrm{mg}$, zaleplon $10 \mathrm{mg}$, and placebo were examined, alone and in combination with alcohol $0.75 \mathrm{~g} / \mathrm{kg} .{ }^{57}$ Eighteen healthy volunteers performed psychomotor tests up to six hours after treatment administration. Blood alcohol concentrations (BAC) at 0.5, 2.0, 4.5, and 6.0 hours after intake were $0.052 \%, 0.037 \%, 0.009 \%$, and $0.001 \%$, respectively. Alcohol impaired most measures up to 4.5 hours after intake. Triazolam with and without ethanol impaired performance on the DSST, symbol copying, reaction time tests, and divided attention test. Zaleplon alone produced no impairment, except at two hours after intake for the DSST and tracking in the divided attention test. Combined with alcohol, the impairment of zaleplon was extended up to 4.5 hours after intake. The effect of coadministration of these agents was additive.

\section{Next-day cognitive, memory and psychomotor functioning}

Benzodiazepine hypnotics have shown residual effects that impair daytime functioning, especially during the morning hours after awakening. Several studies have tested the residual effects of zaleplon. In these studies, zaleplon was administered at bedtime, and performance on a variety of 


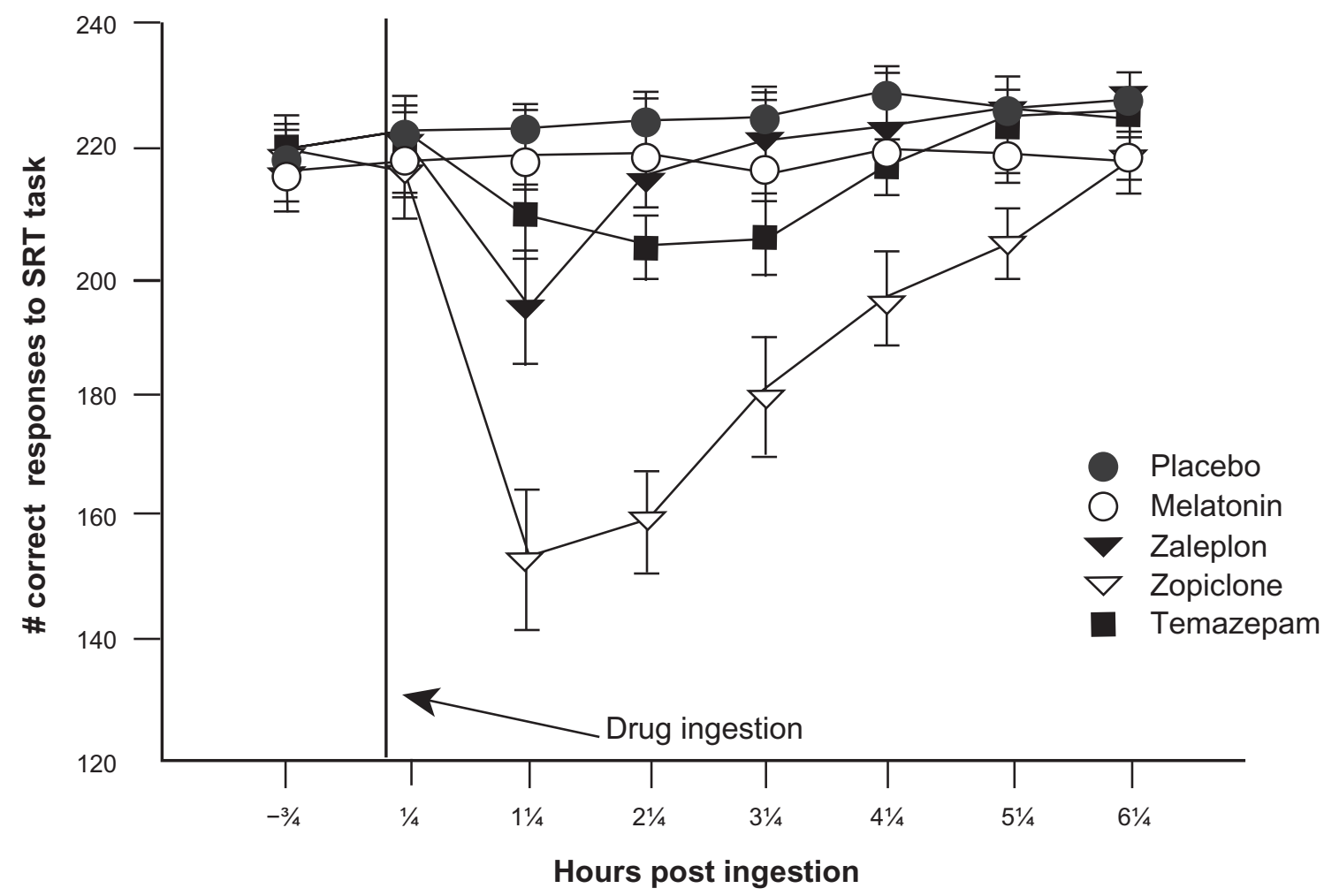

Figure 3 Number of correct responses in a serial reaction time task after ingestion of placebo, time-released melatonin $6 \mathrm{mg}$, zaleplon $10 \mathrm{mg}$, zopiclone $7.5 \mathrm{mg}$, and temazepam 15 mg. Higher number of responses represents better performance. Data are mean values ( \pm standard error of mean) of 23 subjects. Copyright $\odot 2003$. World Association of Sleep Medicine. All rights reserved. Adapted with permission from Paul MA, Gray G, Kenny G, Pigeau RA. Impact of melatonin, zaleplon, zopiclone, and temazepam on psychomotor performance. Aviat Space Environ Med. 2003;74(I2): I263-70.

cognitive, memory and psychomotor test was examined the following day.

Beer et $\mathrm{al}^{13}$ examined memory and psychomotor performance in healthy volunteers after administration of oral doses of $1,5,15,30$, or $60 \mathrm{mg}$ of zaleplon or placebo. Drowsiness and performance on psychomotor tests was impaired in a dose-dependent manner. Memory functioning was not affected. In a double-blind, crossover study, 24 healthy subjects received zaleplon $10 \mathrm{mg}$ and $20 \mathrm{mg}$, zolpidem $10 \mathrm{mg}$ and $20 \mathrm{mg}$, triazolam $0.25 \mathrm{mg}$, or placebo at bedtime. ${ }^{58}$ Tests included word learning, digit span, DSST, paired-associates learning, and divided attention tests, performed after being woken during the night (1.25 hours after intake) and the following morning (8.25 hours after intake). At 1.25 hours after intake, zaleplon $10 \mathrm{mg}$ did not produce any significant changes when compared with placebo, whereas zaleplon $20 \mathrm{mg}$, zolpidem $10 \mathrm{mg}$ and $20 \mathrm{mg}$, and triazolam $0.25 \mathrm{mg}$ caused significant psychomotor impairment. Zaleplon $10 \mathrm{mg}$ and $20 \mathrm{mg}$ and zolpidem $10 \mathrm{mg}$ did not affect performance 8.25 hours after intake. Triazolam $0.25 \mathrm{mg}$ and zolpidem $20 \mathrm{mg}$ showed significant impairment on the DSST.

Walsh et al performed several studies in patients with insomnia. In patients who received zaleplon $5 \mathrm{mg}$ or $10 \mathrm{mg}$ for 14 days, no significant residual effects were found the next morning for performance of simple and complex reaction time tasks, digit span, word learning, and the DSST. ${ }^{24}$ In 48 elderly patients with chronic insomnia, zaleplon $2 \mathrm{mg}, 5 \mathrm{mg}$, or $10 \mathrm{mg}$ also did not affect psychomotor performance the next morning. ${ }^{29}$ Administering higher dosages, Drake et al also found that zaleplon 10-60 mg produced no significant next-morning impairment on the DSST and digit span test in chronic insomniacs. ${ }^{21}$ Although the number of studies is limited, they consistently show absence of performance impairment.

\section{Residual effects after middle- of-the-night administration}

In a double-blind, crossover study, zaleplon $10 \mathrm{mg}$, zolpidem $10 \mathrm{mg}$, or placebo was administered at bedtime to 36 healthy subjects. ${ }^{59}$ Subjects received their treatment 2, 3, 4, or 5 hours before waking. After waking, a psychometric test battery was performed. Zaleplon did not affect performance at any time. In contrast, zolpidem significantly impaired performance on various memory and psychomotor tests for up to 4-5 hours after administration of the drug. 
Hindmarch et al examined the residual effects of zaleplon after middle-of-the-night administration in 40 healthy volunteers. ${ }^{60}$ Zaleplon $10 \mathrm{mg}$ or $20 \mathrm{mg}$, zolpidem $10 \mathrm{mg}$, or placebo was administered at 5 hours, 3 hours, or 1 hour before morning awakening. Critical flicker fusion, choice reaction time, DSST, Sternberg memory scanning, and a word learning test were conducted after morning awakening. Zaleplon $10 \mathrm{mg}$ did not affect performance, except for a significant decrease in DSST scores 1 hour after intake. Zaleplon $20 \mathrm{mg}$ produced a significant increase in choice reaction time, and a decrease in critical flicker fusion threshold, DSST scores, and immediate- and delayed-recall in the word learning test. These effects were significant only when tested 1 hour after intake. In contrast, zolpidem $10 \mathrm{mg}$ produced significant impairment of choice reaction time, memory functioning, DSST, and the critical flicker fusion test up to 5 hours after intake.

In 30 healthy volunteers, the effects of zaleplon $10 \mathrm{mg}$ and $20 \mathrm{mg}$, zolpidem $10 \mathrm{mg}$ and $20 \mathrm{mg}$, and placebo on cognitive, memory, and psychomotor performance were tested four hours after middle-of-the-night administration. ${ }^{61}$ Results were compared with those observed after administration of alcohol (BAC 0.05\%). Zaleplon $10 \mathrm{mg}$ and $20 \mathrm{mg}$, and zolpidem $10 \mathrm{mg}$ did not affect performance on the psychometric tests. In contrast, zolpidem $20 \mathrm{mg}$ and alcohol significantly impaired performance on all psychomotor and memory tests.

Thirteen healthy volunteers participated in a double-blind study to examine the residual effects of zaleplon $10 \mathrm{mg}$ or $20 \mathrm{mg}$, zopiclone $7.5 \mathrm{mg}$, and placebo, 4 hours after a middle-of-the-night administration. ${ }^{62}$ After 5 hours of uninterrupted sleep, subjects were woken to receive treatment, and returned to sleep for another 4 hours. During the second part of the night, subjects were exposed to background noise. In contrast with zopiclone, both dosages of zaleplon did not affect performance on any cognitive tests performed after waking. Zopiclone and zaleplon significantly reduced sleep latency onset when compared with placebo.

Residual effects of zaleplon have also been tested in patients with sleep maintenance insomnia. In a doubleblind, crossover design, 22 patients received zaleplon $10 \mathrm{mg}$, flurazepam $30 \mathrm{mg}$, or placebo in the middle of the night (3.5 hours after bedtime) for two consecutive nights. ${ }^{63}$ The following morning ( 5 to 6.5 hours after treatment administration), flurazepam, but not zaleplon, significantly impaired performance on DSST and symbol copying. When receiving flurazepam, patients reported significantly increased daytime sleepiness.
In 37 adults with sleep-maintenance insomnia, zaleplon $10 \mathrm{mg}$, zolpidem $10 \mathrm{mg}$, or placebo were administered during experimental awakening four hours after bedtime. ${ }^{64}$ Latency to persistent sleep, total sleep time before and after awakening, performance on the DSST, and self-reported alertness and concentration were recorded hourly for 4-7 hours after treatment administration. Both zaleplon and zolpidem significantly reduced latency to persistent sleep and increased total sleep time. Residual effects were significant up to seven hours after administration of zolpidem and four hours after administration of zaleplon.

Taken together, these studies show that the impairment effects of zaleplon are limited to 4 hours after dosing, and in most studies were significant only after administering twice the recommended dose $(20 \mathrm{mg})$.

\section{Effects on driving ability}

Most patients using zaleplon are ambulatory and likely to drive a car. Because driving a car is a common but also potentially dangerous daily activity, several studies have examined the effects of hypnotic drugs on driving ability. ${ }^{65,66}$ These studies showed that benzodiazepine hypnotics significantly impair the ability to drive, and a significantly increased risk of road traffic accidents has been reported for patients using benzodiazepine hypnotics. Several studies have investigated zaleplon in this regard.

In an early study, 28 healthy volunteers received zaleplon at bedtime and were woken after 5 hours to receive placebo, or vice versa ${ }^{67}$ Driving performance was assessed 10 hours after bedtime administration or 5 hours after middle-of-thenight administration of zaleplon $10 \mathrm{mg}$ or $20 \mathrm{mg}$, zopiclone $7.5 \mathrm{mg}$, or placebo. Driving ability was measured by a 100 $\mathrm{km}$ road driving test. The test is performed on a public highway in normal traffic. Subjects were instructed to maintain a steady lateral position and constant speed. Standard deviation of lateral position, ie, weaving of the car, was the primary parameter measured in the test. Zaleplon $10 \mathrm{mg}$ and $20 \mathrm{mg}$ did not affect driving performance. In contrast, zopiclone significantly impaired driving after bedtime and middle-of-the-night administration.

A second study in 30 healthy volunteers also examined road driving performance 10 hours after bedtime administration of zaleplon $10 \mathrm{mg}$, zopiclone $7.5 \mathrm{mg}$, and placebo. ${ }^{68}$ In addition to driving, subjects performed a word learning test, tracking test, and divided attention test. Results were compared with those after administration of alcohol (BAC $0.03 \%$ ). Whereas zopiclone and alcohol significantly impaired driving, memory, and divided attention, zaleplon had no residual effects on driving and the 
psychometric tests. The magnitude of driving impairment after zopiclone was twice that observed after alcohol.

A third study tested driving ability in 30 healthy volunteers four hours after middle-of-the-night administration of zaleplon $10 \mathrm{mg}$ and $20 \mathrm{mg}$, zolpidem $10 \mathrm{mg}$ and $20 \mathrm{mg}$, and placebo. ${ }^{61}$ Zaleplon $10 \mathrm{mg}$ and $20 \mathrm{mg}$ did not significantly impair driving. In contrast, both dosages of zolpidem and alcohol produced significant driving impairment. Whereas an increasing number of sleep-driving events have been reported for zolpidem, ${ }^{69}$ sleep-driving events after using zaleplon are rare. Southworth et $\mathrm{al}^{70}$ described sleep-driving cases for people taking zaleplon, zolpidem, and eszopiclone. Fourteen cases were described, of which 13 involved zolpidem. Only one case involved zaleplon $10 \mathrm{mg}$, but it was used in combination with alcohol and hydrocodone. Another case study described an impaired driver who had used zaleplon. ${ }^{71}$ The concentration of zaleplon determined in the driver's blood was much higher than what would be expected after using the recommended dose of zaleplon. The driver's movements and reactions were slowed, and he showed poor coordination and balance problems.

In conclusion, experimental studies show that, when used as recommended, zaleplon does not appear to impair driving. Currently, no epidemiologic data on road traffic accident risk are available for zaleplon.

\section{Conclusions}

Over the past 20 years, zaleplon has earned its place in insomnia therapy. Efficacy studies show that zaleplon is a suitable hypnotic for sleep initiation purposes. However, because of its short half-life, zaleplon is less effective in sleep maintenance.

The use of zaleplon is relatively safe. Adverse effects are mild and of short duration. Critical interactions have not been reported, and there is no evidence of high abuse potential for zaleplon. Relative to the benzodiazepine hypnotics, the biggest advantage of zaleplon is that there is ample evidence of residual next-day effects. For example, current evidence suggests that as early as four hours after intake, zaleplon does not affect cognitive, memory, and psychomotor performance, or the ability to drive a car in everyday traffic. One should, however, take into account that, when compared with benzodiazepine hypnotics, much less scientific research has been done with zaleplon. Also, many studies with zaleplon have had relatively small sample sizes. Nevertheless, their results were generally consistent with those found in larger studies.
Several topics need to be addressed by future studies or examined in more detail. For example, the efficacy and behavioral effects of long-term zaleplon use have not been examined thoroughly. Most studies are limited to a maximum of 2-4 weeks. Although this is understandable when taking into account the prescription guidelines (the recommended maximal duration of use for zaleplon is two weeks), in reality, a great number of people with insomnia use hypnotics for months or years. In the case of driving, no epidemiologic evidence is available on road traffic accident risk in patients using zaleplon. In addition, there are few data available on interactions of other drugs with zaleplon.

Finally, comparisons with new hypnotics that do not bind to the $\mathrm{GABA}_{\mathrm{A}}$ receptor, such as the melatonin receptor agonist, ramelteon, are important to be able to determine the future role of zaleplon in the treatment of insomnia.

\section{Disclosure}

Verster is a consultant/advisor to Sepracor and Transcept, and has received research support from Wyeth Ayerst Research, Takeda Pharmaceuticals, UCB Pharma, and Red Bull GmbH.

\section{References}

1. Verster JC, Pandi-Perumal SR, Streiner DL. Sleep and Quality of Life in Clinical Medicine. New York, NY: Humana Press (Springer); 2008.

2. Pandi-Perumal SR, Verster JC, Monti JM, Lader MH, Langer SZ. Sleep Disorders: Diagnosis and Therapeutics. London: Informa Healthcare (Taylor and Francis); 2008.

3. Ebben MR, Spielman AJ. Non-pharmacological treatments for insomnia. J Behav Med. 2009;32(3):244-254.

4. Barbera J, Shapiro C. Benefit-risk assessment of zaleplon in the treatment of insomnia. Drug Saf. 2005;28(4):301-318.

5. Dooley M, Plosker GL. Zaleplon: A review of its use in the treatment of insomnia. Drugs. 2000;60(2):413-445.

6. DündarY, Dodd S, Strobl J, Boland A, Dickson R, Walley T. Comparative efficacy of newer hypnotic drugs for the short term management of insomnia: A systematic review and meta-analysis. Hum Psychopharmacol. 2004;19(5):305-322.

7. Hurst M, Noble S. Zaleplon. CNS Drugs. 1999;11(5):387-394.

8. Beer B, et al. A review of the preclinical development of zaleplon, a novel non-benzodiazepine hypnotic for the treatment of insomnia. CNS Drug Rev. 1997;3(3):207-224.

9. Olsen RW, Sieghart W. International Union of Pharmacology. LXX. Subtypes of gamma-aminobutyric acid(A) receptors: Classification on the basis of subunit composition, pharmacology, and function. Update. Pharmacol Rev. 2008;60(3):243-260.

10. Sanna E, Busonero F, Talani G, et al. Comparison of the effects of zaleplon, zolpidem, and triazolam at various $\mathrm{GABA}(\mathrm{A})$ receptor subtypes. Eur J Pharmacol. 2002;451(2):103-110.

11. Damgen K, Luddens H. Zaleplon displays a selectivity to recombinant GABA(A) receptors different from zolpidem, zopiclone and benzodiazepines. Neurosci Res Comm. 1999;25(3):139-148.

12. Doble A. New insights into the mechanism of action of hypnotics. J Psychopharmacol. 1999;13(4 Suppl 1):S11-S20.

13. Beer B, Leni JR, Wu WH, et al. A placebo-controlled evaluation of single, escalating doses of CL 284,846, a non-benzodiazepine hypnotic. J Clin Pharmacol. 1994;34(4):335-344. 
14. Drover D, Lemmens H, Naidu S, Cevallos W, Darwish M, Stanski D. Pharmacokinetics, pharmacodynamics, and relative pharmacokinetic/ pharmacodynamic profiles of zaleplon and zolpidem. Clin Ther. 2000;22(12):1443-1461.

15. Greenblatt DJ, Harmatz JS, von Moltke LL, et al. Comparative kinetics and dynamics of zaleplon, zolpidem, and placebo. Clin Pharmacol Ther. 1998;64(5):553-561.

16. Rosen AS, Fournié P, Darwish M, Danjou P, Troy SM. Zaleplon pharmacokinetics and absolute bioavailability. Biopharm Drug Dispos. 1999;20(3):171-175.

17. Renwick AB, Mistry H, Ball SE, Walters DG, Kao J, Lake BG. Metabolism of zaleplon by human hepatic microsomal cytochrome P450 isoforms. Xenobiotica. 1998;28(4):337-348.

18. Vanover KE, Barrett JE. Evaluation of the discriminative stimulus effects of the novel sedative-hypnotic CL 284,846. Psychopharmacology (Berl). 1994;115(3):289-296.

19. Sakamoto T, Uchimura N, Mukai M, Mizuma H, Shirakawa SI, Nakazawa Y. Efficacy of L-846 in patients with insomnia: Evaluation by polysomnography. Psychiatry Clin Neurosci. 1998;52(2):156-157.

20. Ancoli-Israel S, Walsh JK, Mangano RM, Fujimori M. Zaleplon, a novel nonbenzodiazepine hypnotic, effectively treats insomnia in elderly patients without causing rebound effects. Prim Care Companion J Clin Psychiatry. 1999;1(4):114-120.

21. Drake CL, Roehrs TA, Mangano RM, Roth T. Dose-response effects of zaleplon as compared with triazolam $(0.25 \mathrm{mg})$ and placebo in chronic primary insomnia. Hum Psychopharmacol. 2000;15(8):595-604.

22. Allain H, Bentué-Ferrer D, Breton SL, Polard E, Gandon JM. Preference of insomniac patients between a single dose of zolpidem $10 \mathrm{mg}$ versus zaleplon 10 mg. Hum Psychopharmacol. 2003;18(5):369-374.

23. Zhang H, Shen Y, Liu N, et al. Effect and reliability of zaleplon on treatment of insomnia: A randomized, double-blind, controlled study. Zhongguo Linchuang Kangfu. 2004;8(18):3488-3490.

24. Walsh JK, Fry J, Erwin CW, et al. Efficacy and tolerability of 14-day administration of zaleplon $5 \mathrm{mg}$ and $10 \mathrm{mg}$ for the treatment of primary insomnia. Clin Drug Invest. 1998;16(5):347-354.

25. Elie R, Rüther E, Farr I, Emilien G, Salinas E. Sleep latency is shortened during 4 weeks of treatment with zaleplon, a novel nonbenzodiazepine hypnotic. Zaleplon Clinical Study Group. J Clin Psychiatry. 1999;60(8):536-544.

26. Fry J, Scharf M, Mangano R, Fujimori M. Zaleplon improves sleep without producing rebound effects in outpatients with insomnia. Zaleplon Clinical Study Group. Int Clin Psychopharmacol. 2000;15(3):141-152.

27. Walsh JK, Vogel GW, Scharf M, et al. A five week, polysomnographic assessment of zaleplon $10 \mathrm{mg}$ for the treatment of primary insomnia Sleep Med. 2000;1(1):41-49.

28. Hedner J, Yaeche R, Emilien G, Farr I, Salinas E. Zaleplon shortens subjective sleep latency and improves subjective sleep quality in elderly patients with insomnia. The Zaleplon Clinical Investigator Study Group. Int J Geriatr Psychiatry. 2000;15(8):704-712.

29. Walsh JK, Fry J, Richardson GS, et al. Short term efficacy of zaleplon in older patients with chronic insomnia. Clin Drug Invest. 2000;20(3):143-149.

30. Schwartz T, Nihalani N, Virk S, et al. A comparison of the effectiveness of two hypnotic agents for the treatment of insomnia. Int J Psychiatr Nurs Res. 2004;10(1):1146-1150.

31. Ancoli-Israel S, Richardson GS, Mangano RM, Jenkins L, Hall P, Jones WS. Long term use of sedative hypnotics in older patients with insomnia. Sleep Med. 2005;6(2):107-113.

32. Whitmore JN, Fischer JR Jr, Storm WF. Hypnotic efficacy of zaleplon for daytime sleep in rested individuals. Sleep. 2004;27(5): 895-898.

33. Simons R, Koerhuis CL, Valk PJ, Van den Oord MH. Usefulness of temazepam and zaleplon to induce afternoon sleep. Mil Med. 2006;171(10):998-1001

34. Nicholson AN, Smith PA, Stone BM, Bradwell AR, Coote JH. Altitude insomnia: Studies during an expedition to the Himalayas. Sleep. 1988;11(4):354-361.
35. Beaumont M, Batéjat D, Coste $\mathrm{O}$, et al. Effects of zolpidem and zaleplon on sleep, respiratory patterns and performance at a simulated altitude of 4,000 m. Neuropsychobiology. 2004;49(3):154-162.

36. Beaumont M, Batéjat D, Piérard C, et al. Zaleplon and zolpidem objectively alleviate sleep disturbances in mountaineers at a 3,613 meter altitude. Sleep. 2007;30(11):1527-1533.

37. Jouanin JC, Dussault C, Van Beers P, Piérard C, Beaumont M. Short half-life hypnotics preserve physical fitness and altitude tolerance during military mountainous training. Mil Med. 2009;174(9):964-970.

38. Forrester MB. Comparison of zolpidem and zaleplon exposures in Texas, 1998-2004. J Toxicol Environ Health A. 2006;69(20): 1883-1892.

39. Coyle MA, Mendelson WB, Derchak PA, James SP, Wilson MG. Ventilatory safety of zaleplon during sleep in patients with obstructive sleep apnea on continuous positive airway pressure. J Clin Sleep Med. 2005;1(1):97.

40. Sabbatini M, Crispo A, Pisani A, et al. Zaleplon improves sleep quality in maintenance hemodialysis patients. Nephron Clin Pract 2003;94(4):c99-c103.

41. Darwish M, Martin PT, Cevallos WH, Tse S, Wheeler S, Troy SM. Rapid disappearance of zaleplon from breast milk after oral administration to lactating women. J Clin Pharmacol. 1999;39(7):670-674.

42. Liskow B, Pikalov A. Zaleplon overdose associated with sleepwalking and complex behavior. J Am Acad Child Adolesc Psychiatry. 2004;43(8):927-928.

43. Bhatia SC, Arora M, Bhatia SK. Perceptual disturbances with zaleplon. Psychiatr Serv. 2001;52(1):109-110.

44. Hojer J, Salmonson H, Sundin P. Zaleplon-induced coma and bluishgreen urine: Possible antidotal effect by flumazenil. J Toxicol Clin Toxicol. 2002;40(5):571-572.

45. Louis CJ, Fernandez B, Beaumont C, Pinillos MA, Bardom A, Encina Y. A case of zaleplon overdose. Clin Toxicol (Phila). 2008;46(8):782.

46. Hesse LM, von Moltke LL, Greenblatt DJ. Clinically important drug interactions with zopiclone, zolpidem and zaleplon. CNS Drugs. 2003;17(7):513-532.

47. Sanchez Garcia PS, Carcas A, Zapater P, et al. Absence of an interaction between ibuprofen and zaleplon. Am Health Syst Pharm. 2000;57(12):1137-1141

48. Sanchez Garcia P, Paty I, Leister CA, et al. Effect of zaleplon on digoxin pharmacokinetics and pharmacodynamics. Am J Health Syst Pharm. 2000;57(24):2267-2270.

49. Hetta J, Broman JE, Darwish M, Troy SM. Psychomotor effects of zaleplon and thioridazine coadministration. Eur J Clin Pharmacol. 2000;56(3):211-217.

50. Rush CR, Frey JM, Griffiths RR. Zaleplon and triazolam in humans: Acute behavioral effects and abuse potential. Psychopharmacology (Berl). 1999;145(1):39-51.

51. Allen D, Curran HV, Lader M. The effects of single doses of CL284,846, lorazepam, and placebo on psychomotor and memory function in normal male volunteers. Eur J Clin Pharmacol. 1993;45(4): 313-320.

52. Paul MA, Gray G, Kenny G, Pigeau RA. Impact of melatonin, zaleplon, zopiclone, and temazepam on psychomotor performance. Aviat Space Environ Med. 2003;74(12):1263-1270.

53. Paul MA, Gray G, MacLellan M, Pigeau RA. Sleep-inducing pharmaceuticals: A comparison of melatonin, zaleplon, zopiclone, and temazepam. Aviat Space Environ Med. 2004;75(6):512-519.

54. Mets MA, Volkerts ER, Olivier B, Verster JC. Effect of hypnotic drugs on body balance and standing steadiness. Sleep Med Rev. 2010 Feb 17 [Epub ahead of print].

55. Allain H, Bentué-Ferrer D, Polard E, Akwa Y, Patat A. Postural instability and consequent falls and hip fractures associated with use of hypnotics in the elderly: A comparative review. Drugs Aging. 2005;22(9):749-765.

56. Whitmore JN, Fischer JR, Barton EC, Storm WF. Performance following a sudden awakening from daytime nap induced by zaleplon. Aviat Space Environ Med. 2004;75(1):29-36. 
57. Roehrs T, Rosenthal L, Koshorek G, Mangano RM, Roth T. Effects of zaleplon or triazolam with or without ethanol on human performance. Sleep Med. 2001;2(4):323-332.

58. Troy SM, Lucki I, Unruh MA, et al. Comparison of the effects of zaleplon, zolpidem, and triazolam on memory, learning, and psychomotor performance. J Clin Psychopharmacol. 2000;20(3): 328-337.

59. Danjou P, Paty I, Fruncillo R, et al. A comparison of the residual effects of zaleplon and zolpidem following administration 5 to $2 \mathrm{~h}$ before awakening. Br J Clin Pharmacol. 1999;48(3):367-374.

60. Hindmarch I, Patat A, Stanley N, Paty I, Rigney U. Residual effects of zaleplon and zolpidem following middle of the night administration five hours to one hour before awakening. Hum Psychopharmacol. 2001;16(2):159-167.

61. Verster JC, Volkerts ER, Schreuder AH, et al. Residual effects of middle-of-the-night administration of zaleplon and zolpidem on driving ability, memory functions, and psychomotor performance. J Clin Psychopharmacol. 2002;22(6):576-583.

62. Stone BM, Turner C, Mills SL, et al. Noise-induced sleep maintenance insomnia: Hypnotic and residual effects of zaleplon. Br J Clin Pharmacol. 2002;53(2):196-202.

63. Walsh JK, Pollak CP, Scharf MB, Schweitzer PK, Vogel GW. Lack of residual sedation following middle-of-the-night zaleplon administration in sleep maintenance insomnia. Clin Neuropharmacol. 2000;23(1):17-21.
64. Zammit GK, Corser B, Doghramji K, et al. Sleep and residual sedation after administration of zaleplon, zolpidem, and placebo during experimental middle-of-the-night awakening. J Clin Sleep Med. 2006;2(4):417-423.

65. Verster JC, Veldhuijzen DS, Patat A, Olivier B, Volkerts ER. Hypnotics and driving safety: Meta-analyses of randomized controlled trials applying the on-the-road driving test. Curr Drug Saf. 2006;1(1):63-71.

66. Verster JC, Veldhuijzen DS, Volkerts ER. Residual effects of sleep medication on driving ability. Sleep Med Rev. 2004;8(4):309-325.

67. Vermeeren A, Danjou PE, O'Hanlon JF. Residual effects of evening and middle-of-the-night administration of zaleplon 10 and $20 \mathrm{mg}$ on memory and actual driving performance. Hum Psychopharmacol. 1998;13 Supp1 2:S98-S107.

68. Vermeeren A, Riedel WJ, van Boxtel MP, Darwish M, Paty I, Patat A. Differential residual effects of zaleplon and zopiclone on actual driving: A comparison with a low dose of alcohol. Sleep. 2002;25(2):224-231.

69. Verster JC, Volkerts ER, Olivier B, Johnson W, Liddicoat L. Zolpidem and traffic safety - The importance of treatment compliance. Curr Drug Saf. 2007;2(3):220-226.

70. Southworth MR, Kortepeter C, Hughes A. Nonbenzodiazepine hypnotic use and cases of "sleep driving". Ann Intern Med. 2008;148(6):486-487.

71. Stillwell ME. Zaleplon and driving impairment. J Forensic Sci. 2003;48(3):677-679.
Nature and Science of Sleep

\section{Publish your work in this journal}

Nature and Science of Sleep is an international, peer-reviewed, open access journal covering all aspects of sleep science and sleep medicine, including the neurophysiology and functions of sleep, the genetics of sleep, sleep and society, biological rhythms, dreaming, sleep disorders and therapy, and strategies to optimize healthy sleep. The journal welcomes

\section{Dovepress}

original research, clinical \& epidemiological studies, reviews \& evaluations, case reports and extended reports. The manuscript management system is completely online and includes a very quick and fair peerreview system, which is all easy to use. Visit http://www.dovepress.com/ testimonials.php to read real quotes from published authors. 